\title{
Learning theories and computers in TAFE Education
}

\author{
Gennaro Pellone \\ Richmond College of TAFE
}

\begin{abstract}
The place of the computer in the classroom especially within TAFE Colleges has increased dramatically over the past decade. This paper attempts to describe the role of computers in TAFE education providing some understanding of the principal theoretical models of learning and their relationship with the computer as an educational aid.
\end{abstract}

TAFE Colleges in Australia are increasingly basing their educational practices entirely on competency based learning. This approach to education has been endorsed by two significant events in Australia. The first is the stance taken by the Federal Government and in particular the Right Honourable J. S. Dawkins, MP, Minister for Employment, Education and Training who stated that "the Government has been pressing for the adoption of competency based trade training and has implemented this model in the Australian Traineeship System" (Dawkins, 1988, p.30). The second is the current Award Restructuring which is taking place in industry. This restructuring ensures "that new award structures adequately represent the skills or responsibilities of particular new classifications and that movement between classifications is based on genuine measures of competency" (Dawkins, 1988, p.23).

Therefore, TAFE courses are being developed "on a more systematic module footing, giving them flexibility to fit into the new industry training modular approach', (STB, 1989, p.21). Within this system, student progress is based on the learner achieving certain competencies and not a time serving basis. This means all courses taught at TAFE Colleges have to clearly enunciate the required standard of each student learning performance. When students can perform a task to the prescribed standard then they are able to progress to the next topic. Students are assessed at the completion of each segment, or module, of their course to 
determine if they have successfully achieved the stated criteria, if they pass they proceed on; if they fail they are afforded the opportunity to undertake an alternative learning sequence and then take another test.

Many TAFE Colleges have begun to incorporate, on a large scale, the use of self instructional learning packages which enable students to progress at their own pace uninhibited by group based teacher centred instruction (Rodgers, 1988, pp.3-18). It is within this educational setting, together with the decreased cost of computing power, that computers are beginning to play a major role in TAFE classrooms with "much computer-based educational courseware and software (being) developed locally by teachers on their own initiative" (Hayton, 1984, p.4).

"However, there have also been some illustrations of so-called 'educational' courseware that have been less than adequate from the viewpoint of educational merit" (Schick, in Hayton, 1984, p.35). It must be remembered that it is crucial for teachers, and others who produce computer-based learning materials, to understand what is good and what is bad if education using computers is to improve. "The computer alone, as a piece of equipment, is of little direct interest in education. Only the development of a variety of educational tools and materials based on sound curriculum principles will allow the computer to be useful in education"(Bork, 1985, p.85).

To understand how computers could best serve the learning process we should briefly review what learning is and how it occurs in a more general sense.

\section{Theories of learning}

Many different theories, primarily concerned with questions of how the mind works in relation to the learning process, have been proposed by psychologists over the years. These learning theories can be classified in several categories each emphasising certain aspects of the teachinglearning process more than others. Although, to some extent, "no current learning theory comes close to being complete" (Bork, 1985, p.86), here we present an overview of the contemporary most popular and influential theoretical positions.

\section{Behavioural Theory of Learning}

Behaviourists emphasise a scientifically and carefully controlled approach to the study of behaviour. "They maintain that humans can only deal with the 'stimuli', the inputs to the brain, and the 'responses', the behavioural 
outcomes, of the stimuli" (Bork, 1985, p.86). Basically, classical behaviourists reject any attempt to explain human behaviour in terms of mental entities, eg. desires and intentions, instead they believe that only science can tell us the truth about humans and the world. What is fundamental to science is the scientific method of getting the facts. All statements must be submitted to measurable tests of observation or experiments.

A very influential behavioural approach to learning was the work of B. F. Skinner around 1940. The central notion of Skinner's work is that the actions of animals and human beings depend wholly on rewards and punishments. Skinner, in teaching pigeons to peck very complex patterns, included" simple step-by-step procedures" (Romiszowski, 1984, p.43), in which he rewarded success, usually with food, and, in some situations, punished lack of success. What follows is that in the classroom the behaviour of the student, or the learner, is mainly determined by the behaviour of the teacher. A teacher who respects the importance of the behavioural theory of learning, tells students whether or not they have given the correct answer (feedback), praises them for giving a correct answer (positive reinforcement), or prompts the ones who may need a hint to answer a question (cueing). In these examples, "feedback, positive reinforcement, and cueing" (Favaro, 1986, p.17) are all central concepts in behavioural learning theory.

"Programmed learning, with programmed texts, was also very much influenced by this Skinnerian view of the learning process" (Bork, 1985, p.86). Here great importance is given to the clear and specific descriptions of desired behaviours: "behavioural objectives" (Romiszowski, 1984, p.24). This relates to the philosophy of behaviourism in that only observable behaviours can be measured. Therefore, a behavioural objective is stated in terms which can be observed and measured, and its evaluation and learning strategies are clearly specified so that there is an unprejudiced way of determining whether or not the objective has been achieved. Behaviourists avoid terms like 'know', 'understand', 'appreciate', instead they use words such as 'state', 'explain', 'list', etc. (Rowntree, 1986, p.45).

\section{Cognitive Theory of Learning}

Cognitive theorists take a different point of view. Unlike the behaviourists who, in general, do not find it necessary to hypothesise about the nature of 'thinking', cognitivists believe that there are innate qualities in the human mind and that most learning can be adequately explained in terms of a model of thinking, or cognitive process. Romiszowski (1986, p.33) explains that early cognitive psychologists, including Wertheimer, Kohler, Koffka and Lewis, were mainly concerned with the perception of the form, or 'shape', of objects, patterns or procedures. Hence the German word for 
form - Gestalt - was associated with these viewpoints. Gestalt psychologists placed great emphasis on the problem solving aspect of thinking, the learner's discovery of patterns and relationships, and the transfer of knowledge to new problems. Contemporary cognitive psychologists propose more complex models of learning involving the gradual formation of conceptual schemata. Schematic learning is the using of previously learned ideas, concepts, and so on, in order to understand and simplify new learning. Schemata have a very big influence in determining how new information is processed and how long it is retained.

In practice all this means that good teaching should progress from the known to the unknown, use analogies to explain new concepts, and make topics meaningful if effective learning is to take place. Romiszowski (1984, p.157) also highlights that a further theory of cognitive psychology is that small group work often promotes a more systematic and goal-oriented study of a subject. In small group study all can voice their opinions and let everyone discuss them. More often than not this clarifies any doubt or problem that can arise and stimulates group members to be more critical of their study.

\section{Developmental Theory of Learning}

The developmental theory of learning is an extension of the cognitive theory. It adds the extra consideration of how the learner's mind and learning capacities develop with maturation. Favaro (1986, pp.49-53) explains that Swiss psychologist Jean Piaget has been one of the most influential figures in this field for more than fifty years. His works have been mainly concerned with the processes of children's intellectual development and other mental operations. He found that as children grew older, they continually strived for a more and more comprehensive mastery of their world. From this he concluded that children travelled through a number of major stages of intellectual growth. According to Piaget, the starting point of a child's intellectual development is not related to external influences pressing upon the child, but rather to an internal and continuous growth which stems from the child's own actions. In Piaget's framework, the process of acquiring knowledge is dynamic and interactive. He points out that the span of intellectual development, from birth to maturity, is divisible into four major stages:

1. the 'sensorimotor period' from birth to $18-20$ months), carries the child from inborn reflexes, such as suckling, to a build up of an awareness that something can still exist even if it is hidden from sight;

2. the 'pre-operational period' (18-20 months to 7 years), covers the stage when language is acquired. This allows a child to deal with the world in more conceptual terms rather than in terms of motor activity; 
3. the 'concrete operational period' (7 to 12 years), sees the child perform mental activities, or operations, which are rules of logic necessary to solve tasks of increasing complexity;

4. the 'formal operational stage' (12 to adulthood) characterises the capacity to reason in abstract terms. One can now formulate hypotheses and make logical deductions.

This developmental approach to teaching "has formed the basis of models or theories of instruction developed by such workers as Dienes, Polya, Bruner and Skemp. Much store is laid, in these models, on the learning of important new principles by means of 'discovery' or 'experiential' method" (Romiszowski, 1896, p.37).

\section{Cybernetic Theory of Learning}

"Cybernetics is generally defined as the science of control and communication" (Simons, 1985, p.146). The cybernetic theory of learning is perhaps the most recent formulated position and holds that different types of learning should occur by means of different processes. It integrates from earlier theories useful established concepts such as 'stimulus', 'response', 'conceptual schemata', 'discovery learning', and so on, and combines them to a whole range of new concepts, particularly those concerned with 'selfcontrolling' systems. The cybernetic theory of learning leads us to accept that learners, environment, and learning processes are varied and complex and that no one explanation can hold true in all cases. Cyberneticists believe that learning occurs by means of different processes and it is possible that different learners learn the same material by approaching it from different angles. Work such as that of Gordon Pask (in Romiszowski, 1986, pp.41-42) suggests that individual learners successfully learn by either following a linear path of step by step deduction ('serialist' learning strategy), or by 'jumping ahead' in an attempt to get the 'whole picture' of the topic, returning to study details only when it is necessary for comprehension ('"holist' learning strategy). Pask found that the learning success of individual learners was much superior when the information to be learnt was presented in a way that facilitated the preferred learning strategy.

Different learners learn the same information using different styles and cybernetic principles allow for the control over what is to be learnt in so far that learners are able to create their own learning path. This aspect of cybernetic control stresses the importance of the organisation of the information to be learnt and that of setting up an interactive system which considers student's needs, and learning styles. 


\section{Computers in TAFE education}

With industry moving towards competency-based job structures and through this to competency-based education which promotes self-paced learning, computers in TAFE classrooms are steadily increasing their status. The instructional capabilities of the computer give it several great advantages over many of the other educational media currently in use. Computers can administer lessons and tests giving immediate reinforcement and feedback, allow students to cover course materials at their own pace, involve students to play an active role in the learning process, and can provide the flexibility to cater for an increasingly heterogeneous group of students with a more pronounced mixture of backgrounds and learning styles.

\section{Reinforcement and Feedback}

From an historical perspective, the behavioural theory of learning has been a major authority on both psychology and education. Its philosophy based on behaviour modification in a stimulus-response environment, believes that behaviour is most effectively shaped when such principles as positive reinforcement are applied. The principle of positive reinforcement states that when a positive response is rewarded, the probability of that response happening in the future increases. Rewards don't necessarily have to be tangible, they can take the form of praises or encouragements. A fundamental and easily implemented reinforcement that the computer in the classroom can offer is immediate feedback. Feedback can be defined as knowledge of results and can be provided on the monitor immediately after an appropriate response has been made. Computers can be extremely effective in the delivery of feedback; they never get bored, and can wait patiently for students to respond at their own pace.

Another system of reinforcement is to adapt "an outside contingency management program to performance based on activity around a microcomputer" (Favaro, 1986, p.36). Computers, as well as waiting patiently and providing reinforcement when it's most effective, can also keep excellent records and produce running totals of a student's performance. A way of utilising this feature is for teachers to provide reinforcement based on rewards or privileges in relation to student performance.

\section{Self-paced Learning}

Another behavioural approach to education is to guide students within a large program through a set of modules each containing several behavioural objectives which clearly state the task to be performed, the conditions under which it is to be accomplished, and the standard to be achieved. The modules are organised according to complexity; the easier 
ones first and the more difficult later. This approach offers the advantage for students to work and learn at a rate that suits their individual ability thus progressing through the course at their own pace.

Computers are ideal presenters of information and excellent record keepers in this arrangement. They have the ability to move freely through a program which lets the student have maximum control over the choice of learning objectives; can generate tests to review the understanding of previously learned concepts; access reference data necessary for the execution of practical assignments; monitor student progress; keep records of all student responses and make management decisions as necessary. However, when a program of studies is presented in a modular format there could be a tendency for students to function at the module level and lose perspective of the whole course. Computers can help overcome this problem by offering "a 'menu driven' approach to assist in this self-paced process" (Favaro, 1986, p.39). At the beginning of each session a student would see a menu screen in the form of a progress chart from which to choose various options.

\section{Interaction}

Another major advantage of the computer in the classroom is that it provides interaction. Students learn best when they take an active role in the learning process, as opposed to the passive role that is characteristic of lecture type lesson deliveries, particularly in large classes. Active learning has been developed in response to cognitive theories of learning and suggests that students feel most motivated and learn most efficiently when they do so through their own discoveries. This is not to suggest that teachers abandon their responsibilities, rather it is to consider how can the computer be used to complement classroom practice to encourage active learning. A good teacher in front of a class can provide a rich and sophisticated exposition of its subject, but it is difficult to ensure that students are fully active in the way they learn from it. On the other hand, a good interactive computer-based learning package encourages continuous activity on the part of the student. By combining the two, that is teacher and computer, we can have a medium achieving the same learning gains in a more efficient way. However, "an unfortunate tendency exists to view 'any' interaction as marvellous" (Bork, 1987, p.136). Interaction can occur in various degrees of sophistication, from simple forms where the computer asks for a simple input such as the answer to a multiple choice question, to a higher degree in which the computer analyses the input and then takes some sort of action in order to achieve a more profound effect in the process of learning. It is this high level of interaction that is the desirable feature in establishing a stronger link between the more cognitive theories of learning and computer use. 


\section{Individualisation}

A further important advantage in learning with computers is individualisation. Individualised education allows the student the flexibility in the route taken toward behaviour acquisition and in the selection of learning objectives. Most TAFE courses have been developed according to a modular format, where fairly precise educational or behavioural objectives are specified and mastery of each unit is expected. When all units are completed then the student graduates. The computer, with its capability to generate, retrieve, store, and analyse data, can emulate a real life tutor thus being able to individualise the learning experience.

David Woodhouse (1986, pp.29-31) explains that a number of recent developments herald the influence of Artificial Intelligence techniques. In education much effort is now directed toward intelligent human tutor models. These are consulting systems basically having three components:

1. an 'expert module' which contains a data base or knowledge base of facts, concepts, principles and procedures that the system is to impart;

2. a 'teaching module' which communicates with the student, monitoring, criticising, selecting remedial material, and explaining the reasoning process in problem solving;

3. a 'student module' which represents the student's knowledge status built up over time.

This way of organising courses where allowances are made for learning style and choice pattern of each individual student, where advice is offered on appropriate options based on the individual student's learning record, takes us into the realm of the cybernetic theory of learning.

\section{Conclusion}

Many theories exist which try to explain the process of learning. Each, more than others, tends to emphasise certain aspects of the teachinglearning process. The flexible facilities of the computer enable us to focus on selected aspects of learning theories and implement teaching strategies that would be difficult to realise by other means. Award Restructuring with its emphasis to place skills acquisition at the centre of job classifications, and the shift in TAFE to revolve within competency based self-paced learning systems, make computers an indispensable tool in the classroom. With the development of relatively inexpensive personal computers the possibility of using computers to add to the total learning experience has become more and more available. 


\section{References}

Bork, A. (1985). Personal Computers for Education. New York: Harper and Row.

Bork, A. (1987). Learning with Personal Computers. New York: Harper and Row.

Dawkins, J. S. (1988). Industry Training in Australia: The Need for Change. Canberra: Australian Government Publishing Service.

Favaro, P. J. (1986). Educator's Guide to Microcomputers and Learning. Englewood Cliffs, New Jersey: Prentice-Hall.

Hayton, G. (1984). Computer-Based Educational Software and Courseware in TAFE. Payneham, South Australia: TAFE National Centre for Research and Development.

Rodgers, G. et al. (1988). Teacher Tasks for Self-Paced Learning in TAFE. Victoria: Hawthorn Institute of Education

Romiszowski, A. J. (1984). Producing Instructional Systems: Lesson Planning for Individualised and Group Learning Activities. London: Kogan Page.

Romiszowski, A. J. (1986). Developing Auto-Instructional Materials: From Programmed Texts to CAL and Interacting Video. London: Kogan Page.

Rowntree, D. (1986). Teaching Through Self-Instruction. London: Kogan Page.

Simons, G. (1985). The Biology of Computer Life: Survival, Emotion and Free Will. Sussex: The Harvester Press Publishing Group.

State Training Board (September, 1989). Training Victoria: A User's Guide to the State Training System. Victoria: State Training Board.

Woodhouse, D. and McDougall A. (1986). Computers: Promise and Challenge in Education. Melbourne: Blackwell Scientific.

Author: Gennaro Pellone has been working for the past ten years as an Instructional Designer at the Richmond College of TAFE, 70 Gwynne Street, Richmond, Victoria, 3121. He is also a lecturer in Training and Development at Hawthorn Institute of Education in Victoria.

Please cite as: Pellone, G. (1991). Learning theories and computers in TAFE education. Australian Journal of Educational Technology, 7(1), 39-47. http:/ / www.ascilite.org.au/ajet/ajet7/ pellone.html 